\section{Head and trunk in zebrafish arise via coinhibition of $B M P$ signaling by bozozok and chordino}

\author{
Encina M. Gonzalez, ${ }^{1,3}$ Kimberly Fekany-Lee, ${ }^{1,3}$ \\ Amanda Carmany-Rampey, ${ }^{1}$ Caroline Erter, ${ }^{2}$ \\ Jacek Topczewski, ${ }^{1}$ Christopher V.E. Wright, ${ }^{2}$ \\ and Lilianna Solnica-Krezel ${ }^{1,4}$ \\ ${ }^{1}$ Department of Biological Sciences, Vanderbilt University, \\ and ${ }^{2}$ Department of Cell Biology, Vanderbilt University \\ School of Medicine, Nashville, Tennessee 37235, USA
}

\begin{abstract}
Spatial variations in the levels of bone morphogenetic protein (BMP) signaling are a critical determinant of dorsoanterior-ventroposterior pattern in vertebrate embryos. Whereas BMP overexpression abolishes both head and trunk development, known single and double lossof-function mutations in BMP inhibitors have less dramatic effects. We report that combining mutations in the zebrafish genes bozozok and chordino causes a synergistic loss of head and trunk, whereas most cells express ventro-posterior markers and develop into a tail. Genetic inactivation of BMP signaling fully suppresses these defects. Thus, a remarkably simple genetic mechanism, involving a coinhibition of BMP function by the partially overlapping bozozok and chordino pathways is used to specify vertebrate head and trunk.
\end{abstract}

Received September 20, 2000; revised version accepted October 31, 2000.

During vertebrate development, secreted bone morphogenetic proteins 2/4/7 (BMPs) interact with extracellular antagonists produced by the dorsal (Spemann) gastrula organizer, such as Noggin and Chordin, establishing a ventral to dorsal gradient of BMP activity that specifies cell fates. In the gastrula, epidermis and blood are specified at highest BMP activity, somites are specified laterally, whereas axial mesoderm and neural tissue develop dorsally, at the levels of lowest BMP activity (Sasai et al. 1995; Wilson and Hemmati-Brivanlou 1995; Kishimoto et al. 1997; Nguyen et al. 1998; Nikaido et al. 1999). In frog and fish embryos, establishment of the gastrula organizer is initiated via maternally deposited factors that lead to nuclear accumulation of $\beta$-catenin dorsally (Schneider et al. 1996; Mizuno et al. 1999; Ober and Schulte-Merker 1999). At the onset of zygotic transcription, $\beta$-catenin activates expression of nodal-related

[Key Words: BMP signaling; zebrafish; bozozok; chordino]

${ }^{3}$ These authors contributed equally to this work.

${ }^{4}$ Corresponding author.

E-MAIL Lilianna.Solnica-Krezel@vanderbilt.edu; FAX (615) 343-6707. Article and publication are at www.genesdev.org/cgi/doi/10.1101/ $\operatorname{gad} .852400$. genes together with the homeobox genes bozozok/ dharma/nieuwkoid (bozozok) in zebrafish, and siamois, twin in Xenopus; these genes cooperatively promote organizer formation (Brannon and Kimelmann 1996; Laurent et al. 1997; Fekany et al. 1999; Koos and Ho 1999; Shimizu et al. 2000; Sirotkin et al. 2000).

Ablation of dorsal determinants or other manipulations interfering with the nuclear localization of $\beta$-catenin, and surgical removal of the gastrula organizer, all cause progressive head-to-tail truncations (Scharf and Gerhart 1983; Jesuthasan and Strahle 1997; Mizuno et al. 1999; Ober and Schulte-Merker 1999). Such defects are phenocopied by ectopic BMP signaling in frog and fish embryos (Clement et al. 1995; Kishimoto et al. 1997; Neave et al. 1997), suggesting that inhibition of BMP signaling might be necessary for the specification of head, trunk, and tail tissues. However, various zebrafish and mouse mutations that diminish the ability of the gastrula organizer to limit BMP activity do not lead to a complete loss of head and trunk. The chordino (din) mutations (which inactivate the BMP antagonist Chordin), only mildly ventralize the zebrafish embryo, leading to excess blood and multiple finfolds, but normal AP pattern (Schulte-Merker et al. 1997). Moreover, simultaneous inactivation of din and ogon (ogo), encoding a molecularly uncharacterized negative regulator of BMP, while leading to a more ventralized phenotype than each of the single mutants, does not interfere with the formation of head, trunk, and tail (Miller-Bertoglio et al. 1999). Similarly, chordin;noggin double-mutant mice exhibit a loss of forebrain and axial mesoderm, but maintain a relatively well-formed anterior posterior (AP) axis (Bachiller et al. 2000). Mutations in the zebrafish homeobox gene boz lead to loss of forebrain, midbrain, and axial mesoderm due to an excess of both BMP and Wnt signaling (Koos and Ho 1999; Fekany-Lee et al. 2000). This phenotype is reminiscent of defects resulting from moderate levels of ectopic BMP activity (Kishimoto et al. 1997; Neave et al. 1997; Nguyen et al. 1998).

Inhibition of Nodal signaling by mutations in genes encoding Nodal-related ligands, Squint and Cyclops, also interferes with organizer formation and function, resulting in cyclopic embryos (Feldman et al. 1998; Rebagliati et al. 1998; Sampath et al. 1998). In cyc;sqt double mutants, severe deficiency of head and trunk mesoderm is observed, with apparent complete loss of anterior trunk spinal cord, but relatively normal brain AP pattern (Feldman et al. 1998). Simultaneous inactivation of boz and squint (sqt) or cyclops $(c y c)$ genes leads to more severe organizer deficiencies and anterior truncations than in boz mutants alone, yet both boz;sqt and boz;cyc double mutants exhibit reduced head and trunk structures (Shimizu et al. 2000; Sirotkin et al. 2000). Even boz;sqt;cyc triple mutants develop a very reduced head featuring forebrain (Sirotkin et al. 2000). So far, although these studies suggest that multiple factors function redundantly to limit BMP activity in vivo, the number of early-acting genes involved remains unclear. The genetic 
study presented here identifies the primary factors that are essential for limiting BMP signaling, and thereby provides insight into the early genetic hierarchy underlying head and trunk formation in vertebrate embryos.

\section{Results and Discussion}

To identify the key genes that cooperate in limiting BMP signaling during vertebrate axis formation, we have explored the functional interactions between bozozok (boz) and chordino (din) in zebrafish. Intriguingly, boz mutants exhibit reduced din expression, suggesting that these two genes act in partially overlapping pathways with respect to inhibition of BMP activity (Koos and Ho 1999; Fekany-Lee et al. 2000; Shimizu et al. 2000). To test how simultaneous elimination of boz and din affects BMP inhibition and axis formation, we constructed boz din double mutants. In crosses between $b o z^{\text {m168+ }}$ $\operatorname{din}^{t t 250+}$ fish (Schulte-Merker et al. 1997; Fekany et al. 1999|, two phenotypic classes of boz din double mutants were observed, with variable frequency, at 1-day post fertilization (1 dpf). The less severely affected class exhibited a loss of notochord, severe head truncations, multiple fin folds, and an excess of blood cells near the anus (Fig. 1f,g). The more severely affected class displayed a complete loss of head and trunk structures, a protrusion at one end of the yolk cell, and a tail with $\sim 10$ somites and multiple fin folds (Fig. 1i, inset). The frequency of the strong class of boz din double mutants decreases with age of the female, as observed previously

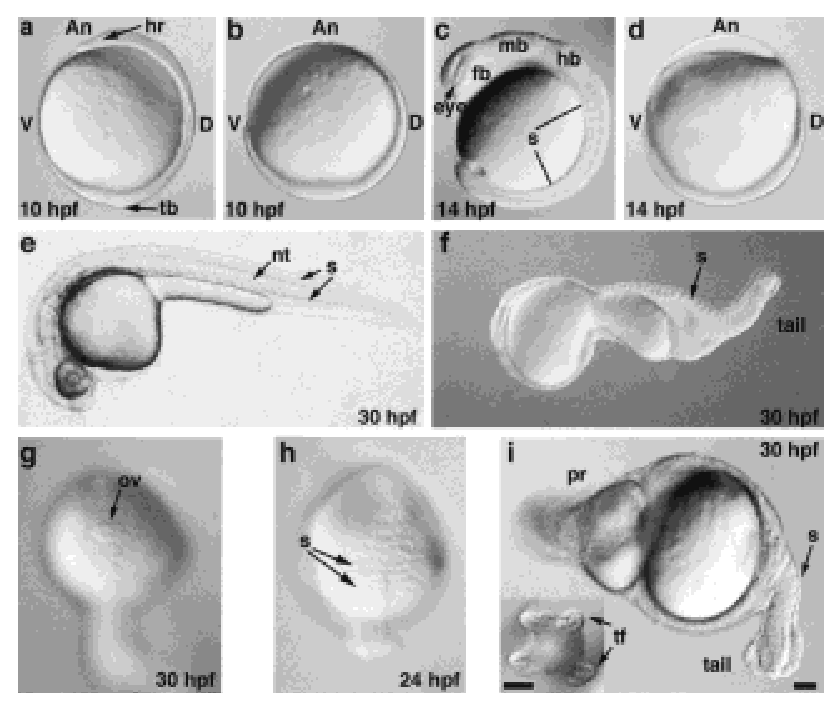

Figure 1. boz din mutant embryos fail to develop a head and trunk. Live $(a, c, e)$ wild-type and $(b, d, f-i)$ boz din mutant embryos at $(a, b) 10 \mathrm{hpf},(c, d) 14 \mathrm{hpf},(h) 24 \mathrm{hpf}$, and $(e-g, i) 30 \mathrm{hpf}$. (g) Single otic vesicle was often found as the most anterior structure in the less affected class of double boz din mutants. (i) Inset shows tail fin duplication. $(a-f, i)$ Lateral views, dorsal to right; (i) dorsal views, anterior to top; $(g)$ anterior view; (An) Animal; (D) dorsal; (V) ventral; (hr) head rudiment; (tb) tailbud; (fb) forebrain; (mb) midbrain; (hb) hindbrain; (nt) notochord; (ov) otic vesicle; (pr) protrusion; (s) somite; (tf) tail fin. Bar, $100 \mu \mathrm{m}$. for the boz mutant phenotype (Fekany et al. 1999). Among the double mutant progeny obtained from a mature female, the strong class constituted 39\% (number of double mutants $=49$; number of total progeny $=459$ ) . Results presented in our work describe the strong double-mutant phenotype. The combined incidence of both classes was lower than expected for independently segregating loci, consistent with boz and din being linked (Fekany et al. 1999). To facilitate further analysis, we utilized boz ${ }^{m 168 /+}$ din $^{t t 250 /+}$ fish, in which recombination placed both mutations on the same chromosome.

To characterize the combined requirement for boz and din in head and trunk development, we analyzed the morphology of boz din mutants and expression of tissuespecific gene markers by whole-mount in situ hybridization (Thisse and Thisse 1998). In wild-type embryos, at the end of gastrulation ( $10 \mathrm{~h}$ post fertilization, hpf), cells had accumulated dorsally on the yolk forming an axis with a head rudiment at the animal pole and a tail bud vegetally (Fig. 1a). In contrast, in boz din mutants, most cells accumulated vegetally, creating a giant tailbud, whereas the head and trunk rudiments were absent. However, boz din mutants exhibited a residual dorsoventral asymmetry in cell accumulation (Fig. 1b). During segmentation, when 10 somites were visible in wild-type siblings (Fig. 1c), the most severely affected boz din mutants had no somites (Fig 1d). At later stages (24 hpf), boz din mutants formed several somites encircling the yolk cell (Fig. 1h) that subsequently resided in the tail (Fig. 1i, $30 \mathrm{hpf})$.

If $b o z$ and din function redundantly in limiting BMP signaling, then the severe morphological defects in boz din mutants should be correlated with greatly increased bmp expression compared with either single mutant. During early gastrulation (6.5 hpf), bmp4 is normally expressed ventrolaterally and in a discrete dorsal domain (Fig. 2a) (Nikaido et al. 1997). The dorsal domain was absent in boz and boz din mutants (data not shown, Fig. $2 b$. Consistent with the above hypothesis, the ventrolateral bmp4 expression domain was more dorsally expanded in boz din mutants compared with either single mutant (Fig. 2b). Similarly, the ventrolateral marker eve1 was more expanded in boz din mutants (Fig. 2c,d) than in either single mutant (data not shown) (Hammerschmidt et al. 1996; Fekany-Lee et al. 2000). Later, during segmentation, the tailbud bmp4 expression domain was almost normal in boz, somewhat expanded in din, but dramatically expanded in boz din embryos (Fig. 2e-h; data not shown). Together, these morphological and gene expression analyses indicated that most cells in boz din mutants resided in the prospective tailbud region within a greatly expanded bmp4 expression domain (cf. Figs. 1 and 2). Furthermore, $b o z$ and din function synergistically in negative regulation of $b m p 4$ expression.

The loss of head and trunk neural tissue in boz din mutants is likely a consequence of widespread bmp expression, because BMP signaling shifts cells from neural to epidermal/nonneural fates (Neave et al. 1997; Sasai and De Robertis 1997; Wilson et al. 1997). gata3, a marker of prospective nonneural ectoderm in wild-type- 


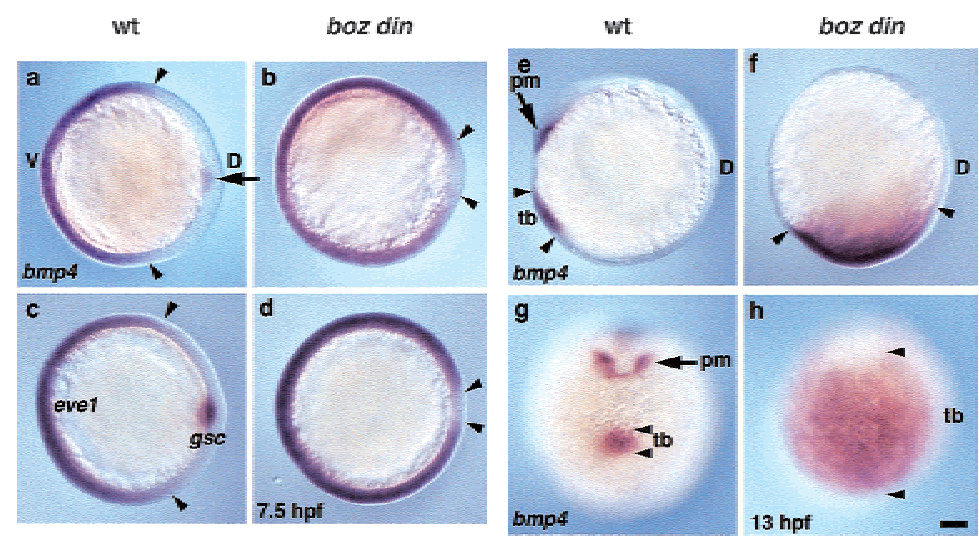

Figure 2. $\quad$ bmp4 expression is greatly expanded in boz din mutants. bmp4 expression in $(a)$ wild-type $(\mathrm{wt})$ and $(b)$ boz din embryos at mid-gastrulation (7.5 hpf). Ventro-lateral eve1 expression and organizer-specific expression of gsc was used to distinguish $(c)$ wild-type and $(d)$ boz din embryos at midgastrulation (7.5 hpf). bmp4 expression in $(e, g)$ wild-type and $(f, h)$ boz din embryos during somitogenesis (13 hpf). (a-d) Anterior views, dorsal to right; $(e, f)$ lateral views, dorsal to right; $(g, h)$ ventral views. Arrowheads indicate borders of $(a-d)$ ventro-lateral and $(e-h)$ posterior domains of bmp4 and eve1 expression; arrow indicates $(a)$ dorsal domain and $(e, g)$ anterior bmp4 expression domain absent in boz din. (pm) Prechordal mesoderm; (tb) tailbud. Bar, $100 \mu \mathrm{m}$.

late gastrulae (Fig. 3a), was moderately expanded in boz and din mutants (data not shown) (Neave et al. 1995; Fekany-Lee et al. 2000). In contrast, in boz din embryos, gata3 expression spread dorsally, revealing a severe reduction of prospective neural ectoderm (Fig. 3b). $\mathrm{HuC}$ expression, marking neuronal precursors along the entire axis in wild-type embryos (Fig. 3c; Kim et al. 1996), was limited to a few putative tail neurons in boz din mutants (Fig. 3d). Furthermore, markers of the forebrain (six3), midbrain-hindbrain boundary (pax2.1), and hindbrain rhombomeres 3 and 5 (krox20) were absent in boz din mutants (Fig. 4e,f; Krauss et al. 1991; Oxtoby and Jowett 1993; Kobayashi et al. 1998). Therefore, boz din mutants display a dramatic reduction of head and trunk neuroectoderm, and a concomitant expansion of nonneural ectoderm.

To investigate the defects underlying the apparent loss of head and trunk mesoderm in boz din mutants (Fig. 1i), we analyzed early mesendoderm development. During gastrulation, the panmesodermal marker no tail ( $n t l)$ is expressed in marginal mesoderm and dorsally in notochord precursors (Schulte-Merker et al. 1994). Although presumptive notochordal ntl expression was missing, marginal $n t l$ expression encircled boz and boz din mutants throughout gastrulation, as in wild type (data not shown) (Hammerschmidt et al. 1996a; Fekany et al. 1999). Furthermore, two nodal-related genes essential for mesoderm formation, cyclops and squint (Feldman et al. 1998; Rebagliati et al. 1998; Sampath et al. 1998), were expressed normally in the blastoderm margin of boz din mutant blastulae. boz din mutants also retained endodermal expression of sox17 (data not shown) and axial, but the chordamesoderm expression in the last one was missing (Fig. 3e,f) (Alexander and Stainier 1999).
Hence, initial stages of mesendoderm formation are not affected in boz din mutants, in contrast to Nodal signaling-deficient embryos (Feldman et al. 1998).

To investigate subsequent steps of mesoderm development, we analyzed $n t l$ expression during segmentation, normally detected in the differentiating notochord and in tailbud mesodermal precursors (Fig. 3g). The notochordal $n t l$ expression domain was reduced in din and absent in boz and boz din mutants (Fig. 3g,h) (Hammerschmidt et al. 1996a; Fekany et al. 1999|. However, the tailbud mesodermal expression domain was normal in boz, expanded in din, and dramatically enlarged in boz din mutants, consistent with the massive accumulation of cells in this region, as mentioned above (cf. Fig. 3h with Fig. lb; data not shown). Similarly, tailbud expression of the mesodermal marker paraxial protocadherin (papc) was expanded in boz din compared with single mutants (Fig. 4a,b; data not shown) (Yamamoto et al. 1998). Conversely, expression of somitic markers, including papc and myoD (Weinberg et al. 1996) was not observed during early somitogenesis in boz din mutants, in contrast to single mutants (Fig. 4b). At the 15 -somite stage, myoD marked an equivalent number of somites in wild-type, boz, and din embryos, but their number and size were greatly reduced in boz din mutants (Fig. 3i,j; data not shown). Together these studies suggest that in boz din mutants, an excess of mesoderm is present in the tailbud region at the expense of trunk somitic mesoderm.

We next determined whether the loss of somitic mesoderm in boz din embryos can be attributed to a transformation into ventral mesoderm. Expression of gata1, which marks blood precursors (Fig. 3g; Detrich et al. 1995), was normal in boz and slightly increased in din mutants (Hammerschmidt et al. 1996a; data not shown). In boz din mutants, gata1-positive cells were distributed abnormally, forming a narrow stripe around the embryonic circumference. Their number, however, was not greater than in din alone (Fig. 3h).

To further investigate the character of vegetally accumulating mesoderm in boz din mutants, we analyzed caudal (cad) expression, a marker of ventro-posterior mesoderm and ectoderm (Fig. 3k; Joly et al. 1992). Although the cad expression domain was enlarged in din mutants (data not shown), it was severely expanded toward the animal pole in boz din mutants such that most of the cells present in the embryo expressed cad (cf. Fig. 31 to Fig. 1b). Together these studies indicate that, whereas mesoderm is induced normally around the blastoderm margin of boz din mutants, during later development it accumulates vegetally and is misspecified toward a posterior character.

To investigate whether locally increased cell death contributed to the loss of dorso-anterior tissues in boz din mutants, we performed TUNEL analysis (Abdelilah et al. 1996). The number of apoptotic cells at 12 somites in boz mutants was similar to wild type (Fig. $3 \mathrm{~m}$; data 


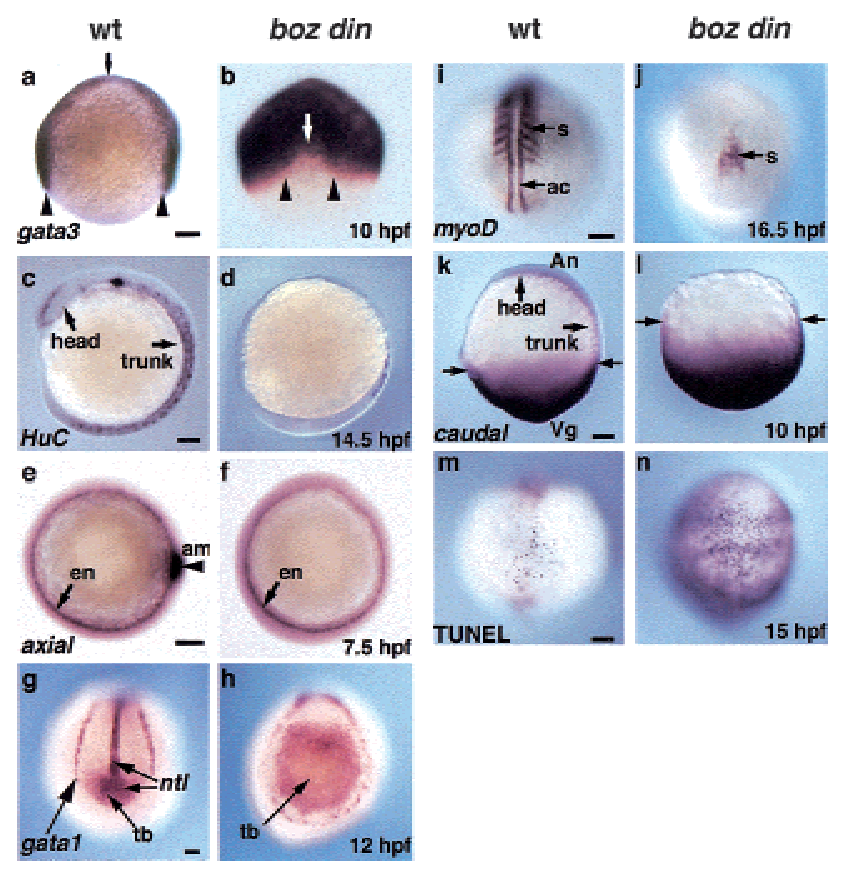

Figure 3. boz din mutants exhibit reduced neuroectoderm and dorsal mesoderm and expanded nonneural ectoderm and ventroposterior tissues. gata3 expression in nonneural ectoderm in $(a)$ wild type (wt) and (b) boz din mutants at $10 \mathrm{hpf}$. Arrowheads indicate width of the neural plate, arrows indicate anterior border of the neural plate. Neuronal $\mathrm{HuC}$ expression in $(c)$ wild type and $(d)$ boz din at 14.5 hpf. axial expression in endoderm and axial mesoderm $(e)$ wild type and $(f)$ boz din mutants at 7.5 hpf. $n t l$ and gata1 expression in $(g)$ wild type and $(h)$ boz din at 12 hpf. myoD expression in (i) wild type and (j) boz din at 15 somites (16.5 hpf). cad expression in (k) wild type and (1) boz din at $10 \mathrm{hpf}$. Arrows denote posterior border of cad expression. Cell death visualized by TUNEL staining in $(m)$ wild type and $(n)$ boz din at 15 hpf. $(a, b)$ Animal view, dorsal to left $(a) ;(c, d, i, j)$ dorsal views, anterior to top; $(e, f, k, l)$ lateral views, anterior to top; $(g, h, m, n)$ dorso-posterior views, anterior to top; (am) axial mesoderm; (en) endoderm; (s) somites; (ac) adaxial cells; (tb), tailbud. Bar, $100 \mu \mathrm{m}$.

not shown), increased posteriorly in din mutants (Hammerschmidt et al. 1996a), but greatly increased throughout boz din mutants (Fig. 3n). Whereas the increase in cell death in all regions of boz din mutants may contribute to a global tissue loss, it cannot account for the specific deficiency of head and trunk.

Next we asked whether the synergistic loss of head and trunk in boz din mutants is solely the result of excess BMP activity or redundant, BMP-independent functions of boz and din. To address this issue, we used the swirl ${ }^{t c 300}$ (swr) mutation, which inactivates the bmp2b locus and leads to down-regulation of bmp4 and $b m p 7$ and consequently to a dorsalized phenotype (Kishimoto et al. 1997; Nguyen et al. 1998; Schmid et al. 2000). First, we examined phenotypes of din;swr and boz;swr double mutants. Double din;swr mutants and swr single mutants exhibit an identical dorsalized phenotype, consistent with din acting exclusively in a BMP-dependent manner (Hammerschmidt et al. 1996b). In contrast, in boz;swr mutants, the neural induction deficit of boz was suppressed, but not the notochord or forebrain deficiencies. The uninterrupted circumferential expression of the presomitic mesodermal marker papc indicated that ventrolateral mesoderm was dorsalized as in $s w r$ mutants and that the notochord was absent as in boz mutants (Fig. 4d). Further, reduced six3 expression in the forebrain, a hallmark of the boz phenotype (Fekany-Lee et al. 2000), was also observed in boz;swr mutants (Fig. 4h). However, markers of the midbrain-hindbrain boundary (pax2.1) and hindbrain (krox20) encircled the embryo in boz;swr mutants (Fig. 4h), as observed for $s w r$ mutants (Fig. 4g). These observations are consistent with the results of inhibiting BMP signaling in boz mutants by overexpressing Chordin or Noggin, and genetically confirm that the notochord and forebrain deficiencies in boz are caused by a BMP-independent defect (Fekany-Lee et al. 2000). Finally, we analyzed the boz din;swr triple mutants. Because swr is epistatic to din (Hammerschmidt et al. 1996b), if the synergistic loss of head and trunk in boz din mutants is due solely to excess BMP activity, the boz din;swr triple and boz;swr double-mutant phenotypes should be identical. boz din;swr triple mutants exhibited circumferential papc expression, indicating that the ventral mesoderm was dorsalized, and the notochord was still absent (Fig. 4d), just like boz;swr. In addition, the ectoderm was completely neuralized, but the forebrain was still reduced (Fig. 4h). These epistatic analyses demonstrate that the synergistic loss of head and trunk in boz din mutants is due to excessive BMP signaling. Hence, boz and din have redundant functions in inhibition of BMP activity during head and trunk development.

For the first time, our studies show that simultaneous inactivation of the zygotic functions of only two genes, $b o z$ and din, can result in embryos without a head and trunk. To date, this dramatic phenotype has only been generated by embryological manipulations such as early removal of dorsal determinants or high-level BMP overexpression (Scharf and Gerhart 1983; Clement et al. 1995; Jesuthasan and Strahle 1997; Kishimoto et al. 1997; Neave et al. 1997; Ober and Schulte-Merker 1999). As removal of dorsal determinants from vegetal pole of zebrafish zygote results in loss of boz and din expression (Ober and Schulte-Merker 1999), we hypothesize that these two genes identify the two main pathways activated by dorsal determinants to limit BMP signaling during head and trunk development. Although boz din mutants have severe axis truncations, they still exhibit some dorsal-ventral polarity at the gastrula stage, and form a rudimentary tail (Figs. $1 \mathrm{~b}, \mathrm{i}$ and $2 \mathrm{a}, \mathrm{b}$ ). Therefore, boz din may not completely remove anti-BMP functions, raising the possibility that another BMP antagonist(s) is residually active in these mutant embryos.

The findings described here show that several distinct effects of high BMP activity cause the head/trunk deficiency in boz din double mutants. Within the ectoderm, high levels of BMP activity transform the neuroectoderm into nonneural ectoderm, consistent with previous reports (Neave et al. 1997; Sasai and De Robertis 1997; 

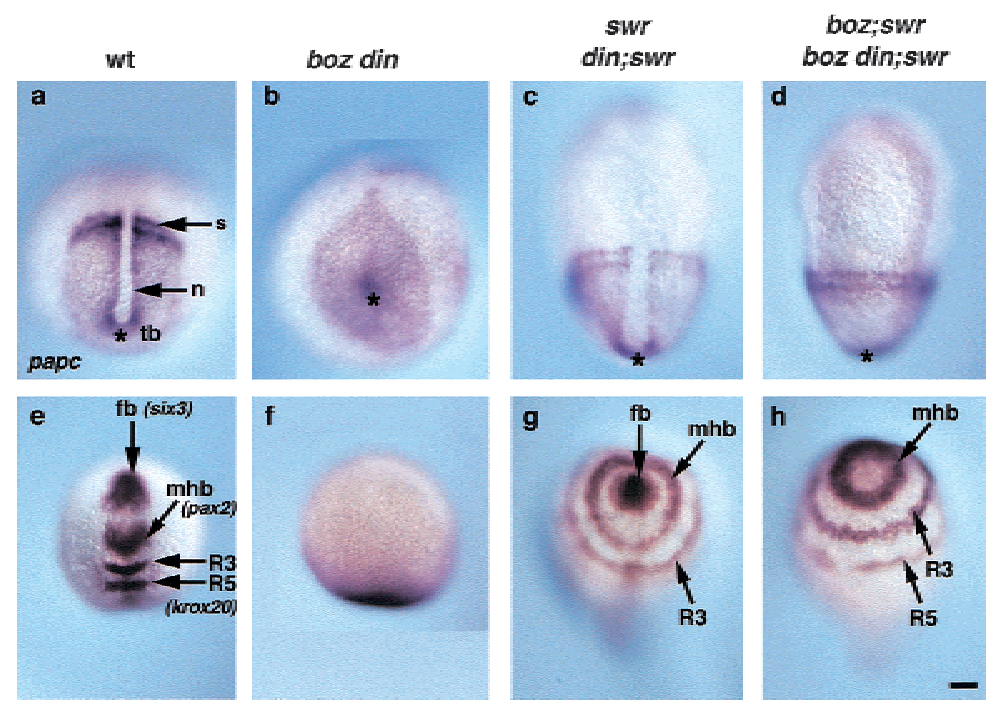

Figure 4. The synergistic defects of boz din mutants are suppressed in boz din;swr (bmp2b) mutants. Because $s w r$ is epistatic to din (Hammerschmidt et al. 1996b), the phenotype of swr and din;swr and likewise of boz;swr and boz din;swr were identical. papc expression in $(a)$ wild type, $(b)$ boz din, $(c)$ swr (or din;swr), and (d) boz din;swr (or boz;swr) at 2-4 somites. (*) Position of the tailbud. six3 (fb), pax2.1 (mhb), and krox20 (R3 and R5) expression in (e) wild type, (f) boz din, ( $g$ ) swr (or din;swr), and (h) boz din;swr (or boz;swr). (a-d), Dorsal views, anterior to top; (e-h), dorso-anterior views; (s), somites; $(\mathrm{n})$ notochord; $(\mathrm{tb})$ tailbud; $(\mathrm{fb})$ forebrain; $(\mathrm{mhb})$ midbrain-hindbrain boundary; (R3) rhombomere 3; (R5) rhombomere 5. Bar, $100 \mu \mathrm{m}$.

Wilson et al. 1997). Our data suggest that almost all of the mesodermal precursors in boz din mutants experience very high levels of BMP activity and, instead of contributing to head and trunk, are misallocated to the tailbud, express ventro-posterior markers, and form a tail. This idea is in accord with fate-mapping studies showing that ventral cells in the zebrafish gastrula migrate to the tailbud and contribute to the tail (Kimmel et al. 1990; Kanki and Ho 1997), and this behavior is expanded dorsally in mutants with elevated BMP activity (D. Myers and L. Solnica-Krezel, unpubl.). Therefore, we propose that the high levels of BMP signaling in boz din

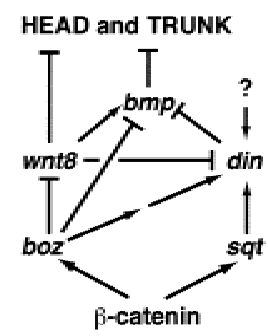

Figure 5. boz and din act in redundant, partially overlapping pathways to inhibit BMP function and specify head and trunk formation. Inactivation of boz leads to BMP-independent defects due to excess of Wnt (most likely Wnt8) signaling. Expression of din during late gastrulation is regulated by boz and sqtindependent mechanism (marked by ?), as boz;sqt double mutants are less ventralized than boz din double mutants (Hammerschmidt et al. 1996a; Fekany-Lee et al. 2000; Shimizu et al. 2000; Sirotkin et al. 2000). embryos specify posterior structures at the expense of anterior structures. This proposal is consistent with the phenotype of BMP signaling mouse mutants, in which the major defect arises in posterior structures, such as the tail and allantois (Winnier et al. 1995). In summary, boz and din represent the major overlapping pathways (Fig. 5) that are absolutely essential to limit BMP activity dorso laterally and allow head and trunk formation in the vertebrate embryo.

\section{Materials and methods}

Fish strains

For all studies performed here, we used the $m 168$ allele of boz encoding a truncated protein without a homeodomain (Fekany et al. 1999). m168 is considered to be a strong allele, however, low amounts of wild-type activity have been reported for this allele (Koos and Ho 1999). The tt250 allele of din was used, encoding a truncated protein that lacks all the cysteine-rich repeats (Schulte-Merker et al. 1997). The tc300 allele of swr was used, in which a tryptophan is substituted for one of the conserved cysteine residues (Kishimoto et al. 1997).

\section{Genotyping}

Live embryos were genotyped by PCR using a restriction polymorphism introduced by ENU mutations. Single live embryos at $10-24 \mathrm{hpf}$ were digested in $2.8 \mathrm{mg} / \mathrm{mL}$ Proteinase $\mathrm{K}$ overnight at $65^{\circ} \mathrm{C}$. After boiling for $10 \mathrm{~min}, 2 \mu \mathrm{L}$ of digested solution served as a template in a $10-\mu \mathrm{L}$ PCR reaction. boz;swr embryos showed a variable phenotype, similar to boz single mutants and occurred at an average frequency of $1.4 \%(n=1085)$. boz din;swr embryos exhibited a more stable phenotype and the combination of boz;swr and boz din;swr embryos observed was $2.4 \%(n=1609)$.

\section{Acknowledgments}

We thank B. Appel, B. Hogan, and members of our laboratories for critical discussions and comments on the manuscript. We acknowledge B. Heher for fish care. We are grateful to Dr. M Halpern for the gift of din fish and a method for genotyping $d i n^{t t 250 /+}$ mutants. swr fish were kindly provided by Dr. M. Mullins. This work was supported by a NIH training grant (K.F.L.), a postdoctoral fellowship from UCM, Spain (E.M.G.), and a grant from the March of Dimes Birth Defects Foundation no. FY990480 and from NIH no. GM55101 to L.S.K., who is a Pew Scholar.

The publication costs of this article were defrayed in part by payment of page charges. This article must therefore be hereby marked "advertisement" in accordance with 18 USC section 1734 solely to indicate this fact.

\section{References}

Abdelilah, S., Mountcastle-Shah, E., Harvey, M., Solnica-Krezel, L., Schier, A.F., Stemple, D.L., Malicki, J., Neuhauss, S.C.F., Zwartkruis, F., Stainier, D.Y.R., et al. 1996. Mutations affecting neural survival in zebrafish. Development 123: 217-227.

Alexander, J. and Stainier, D.Y. 1999. A molecular pathway leading to endoderm formation in zebrafish. Curr. Biol. 9: 1147-1157.

Bachiller, D., Klingensmith, J., Kemp, C,. Belo, J.A., Anderson, R.M., May, S.R., McMahon, J.A., McMahon, A.P., Harland, R.M., Rossant, J., et al. 2000. The organizer factors Chordin and Noggin are required for mouse forebrain development. Nature 403: 658-661.

Brannon, M. and Kimelmann, D. 1996. Activation of Siamois by the Wnt Pathway. Dev. Biol. 180: 344-347.

Clement, J.H., Fettes, P., Knochel, S., Lef, J., and Knochel, W. 1995. Bone morphogenetic protein 2 in the early development of Xenopus laevis. Mech. Dev. 52: 357-370.

Detrich III, H.W., Kieran, M.W., Chan, F.Y,. Barone, L.M., Yee, K., Rundstadler, J.A., Pratt, S., Ransom, D., and Zon, L.I. 1995. Intraembryonic 
hematopoietic cell migration during vertebrate development. Proc. Nat1. Acad. Sci. 92: 10713-10717.

Fekany, K., Yamanaka, Y., Leung, T., Sirotkin, H.I., Topczewski, J., Gates, M.A., Hibi, M., Renucci, A., Stemple, D., Radbill, A., et al. 1999. The zebrafish bozozok locus encodes Dharma, a homeodomain protein essential for induction of gastrula organizer and dorsoanterior embryonic structures. Development 126: 1427-1438.

Fekany-Lee, K., Gonzalez, E., Miller-Bertoglio, V., and Solnica-Krezel, L. 2000. The homeobox gene bozozok promotes anterior neuroectoderm formation in zebrafish through negative regulation of BMP24 and Wnt pathways. Development 127: 2333-2345.

Feldman, B., Gates, M.A., Egan, E.S., Dougan, S.T., Rennebeck, G., Sirotkin, H.I., Schier, A.F., and. Talbot, W.S. 1998. Zebrafish organizer development and germ-layer formation require nodal-related signals. Nature 395: 181-185.

Hammerschmidt, M., Pelegri, F., Mullins, M.C., Kane, D.A., van Eeden, F.J.M., Granato, M. Brand, M., Furutani-Seiki, M., Hafter, P., Heisenberg, C.-P., et al. 1996a. dino and mercedes, two genes regulating dorsal development in the zebrafish embryo. Development 123: 95102.

Hammerschmidt, M., Serbedzija, G.N., and McMahon, A. 1996b. Genetic analysis of dorsoventral pattern formation in the zebrafish: Requirement of BMP-like ventralizing activity and its dorsal repressor. Genes \& Dev. 10: 2452-2461.

Jesuthasan, S. and Strahle, U. 1997. Dynamic microtubules and specification of the zebrafish embryonic axis. Curr. Biol. 7: 31-42.

Joly, J.S., Maury, M., Joly, C., Duprey, P., Boulekbache, H., and Condamine, H. 1992. Expression of a zebrafish caudal homeobox gene correlates with the establishment of posterior cell lineages at gastrulation. Differentiation 50: 75-87.

Kanki, J.P. and Ho, R.K. 1997. The development of the posterior body in zebrafish. Development 124: 881-893.

Kim, C.H., Ueshima, E., Muraoka, O., Tanaka, H., Yeo, S.Y., Huh, T.L., and Miki, N. 1996. Zebrafish elavHuC homologue as a very early neuronal marker. Neurosci. Lett. 216: 109-112.

Kimmel, C.B., Warga, R.M., and Schilling, T.F. 1990. Origin and organization of the zebrafish fate map. Development 108: 581-594.

Kishimoto, Y., Lee, K.H., Zon, L., Hammerschmidt, M., and SchulteMerker, S. 1997. The molecular nature of zebrafish swirl: BMP2 function is essential during early dorsoventral patterning. Development 124: $4457-4466$

Kobayashi, M., Toyama, R., Takeda, H., Dawid, I.B., and Kawakami, K. 1998. Overexpression of the forebrain-specific homeobox gene six3 induces rostral forebrain enlargement in zebrafish. Development 125: 2973-2982.

Koos, D.S. and Ho, R.K. 1999. The nieuwkoiddharma homeobox gene is essential for bmp2b repression in the zebrafish pregastrula. Dev. Biol. 215: 190-207.

Krauss, S., Johansen, T., Korzh, V., and Fjose, A. 1991. Expression of the zebrafish paired box gene pax[zf-b] during early neurogenesis. Development 113: 1193-1206.

Laurent, M.N., Blitz, I.L., Hashimoto, C., Rothbacher, U., and Cho, K.W. 1997. The Xenopus homeobox gene twin mediates Wnt induction of goosecoid in establishment of Spemann's organizer. Development 124: 4905-4916.

Miller-Bertoglio, V., Carmany-Rampey, A., Furthauer, M., Gonzalez, E.M., Thisse, C., Thisse, B., Halpern, M.E., and Solnica-Krezel, L. 1999. Maternal and zygotic activity of the zebrafish ogon locus antagonizes BMP signaling. Dev. Biol. 214: 72-86.

Mizuno, T., Yamaha, E., Kuroiwa, A., and Takeda, H. 1999. Removal of vegetal yolk causes dorsal deficencies and impairs dorsal-inducing ability of the yolk cell in zebrafish. Mech. Dev. 81: 35-47.

Neave, B., Rodway, A., Wilson, S.W., Patient, R., and Holder, N. 1995. Expression of zebrafish GATA3 (gta3) during gastrulation and neurulation suggests a role in the specification of cell fate. Mech. Dev. 51: $169-182$.

Neave, B., Holder, N., and Patient, R. 1997. A graded response to BMP-4 spatially coordinates patterning of the mesoderm and ectoderm in the zebrafish. Mech. Dev. 62: 183-195.

Nguyen, V.H., Schmid, B., Trout, J., Connors, S.A., Ekker, M., and Mullins, M.C. 1998. Ventral and lateral regions of the zebrafish gastrula, including the neural crest progenitors, are established by a bmp2bswirl pathway of genes. Dev. Biol. 199: 93-110.
Nikaido, M., Tada, M., Saji, T., and Ueno, N. 1997. Conservation of BMP signaling in zebrafish mesoderm patterning. Mech. Dev. 61: 75-88.

Nikaido, M., Tada, M., Takeda, H., Kuroiwa, A., and Ueno, N. 1999. In vivo analysis using variants of zebrafish BMPR-IA: Range of action and involvement of BMP in ectoderm patterning. Development 126: 181-190.

Ober, E.A. and Schulte-Merker, S. 1999. Signals from the yolk cell induce mesoderm, neuroectoderm, the trunk organizer, and the notochord in zebrafish. Dev. Biol. 215: 167-181.

Oxtoby, E. and Jowett, T. 1993. Cloning of the zebrafish krox-20 gene (krx-20) and its expression during hindbrain development. Nucleic Acids Res. 210: 1087-1095.

Rebagliati, M.R., Toyama, R., Haffter, P., and Dawid, I.B. 1998. cyclops encodes a nodal-related factor involved in midline signaling. Proc. Nat1. Acad. Sci. 95: 9932-9937.

Sampath, K., Rubinstein, A.L., Cheng, A.M.S., Liang, J.O., Fekany, K., Solnica-Krezel, L., Korzh, V., Halpern, M.E., and. Wright, C.V.E. 1998. Induction of the zebrafish ventral brain and floor plate requires CyclopsNodal Signaling. Nature 395: 185-189.

Sasai, Y. and De Robertis, E.M. 1997. Ectodermal patterning in vertebrate embryos. Dev. Biol. 182: 5-20.

Sasai, Y., Lu, B., Steinbeisser, H., and De Robertis, E.M. 1995. Regulation of neural induction by the chordin and Bmp-4 antagonistic patterning signals in Xenopus. Nature 376: 333-337.

Scharf, S.R. and Gerhart, J.C. 1983. Axis determination in eggs of Xenopus laevis: A critical period before first cleavage, identified by the common effects of cold, pressure and ultraviolet irradiation. Dev. Biol. 99: 75-87.

Schmid, B., Furthauer, M., Connors, S.A., Trout, J., Thisse, B., Thisse, C., and Mullins, M.C. 2000. Equivalent genetic roles for bmp7snailhouse and bmp2bswirl in dorsoventral pattern formation. Development 127: 957-967.

Schneider, S., Steinbesser, H., Warga, R.M., and Hausen, P. 1996 $\beta$-catenin translocation into nuclei demarcates the dorsalizing centers in frog and fish embryos. Mech. Dev. 57: 191-198.

Schulte-Merker, S., VanEeden, F.J.M., Halpern, M.E., Kimmel, C.B., and Nusslein-Volhard, C. 1994. No tail (Ntl) is the zebrafish homologue of the mouse T (brachyury) gene. Development 120: 1009-1015.

Schulte-Merker, S., Lee, K.J., McMahon, A.P., and Hammerschmidt, M. 1997. The zebrafish organizer requires chordino. Nature 387: 862863.

Shimizu, T., Yamanaka, Y., Ryu, S., Hashimoto, H., Yabe, T., Hirata, T., Bae, Y., Hibi, M., and Hirano, T. 2000. Cooperative roles of BozozokDharma and Nodal-related proteins in the formation of the dorsal organizer in zebrafish. Mech. Dev. 91: 293-303.

Sirotkin, H.I., Dougan, S.T., Schier, A.F., and Talbot, W.S. 2000. bozozok and squint act in parallel to specify dorsal mesoderm and anterior neuroectoderm in zebrafish. Development 127: 2583-2592.

Smith, W. and Harland, R. 1992. Expression cloning of noggin, a new dorsalizing factor localized to the Spemann organizer in Xenopus embryos. Cell 70: 829-840.

Thisse, C. and Thisse, B. 1998. High resolution whole-mount in situ hybridization. Zebrafish science monitor 5: 8-9.

Weinberg, E.S., Allende, M.L., Kelly, C.S., Abdelhamid, A., Murakami, T., Andermann, P., Doerre, O.G., Grunwald, D.J., and Riggleman, B. 1996. Developmental regulation of zebrafish MyoD in wild-type, no tail and spadetail embryos. Development 122: 271-280.

Wilson, P.A. and Hemmati-Brivanlou, A. 1995. Induction of epidermis and inhibition of neural fate by Bmp-4. Nature 376: 331-333.

Wilson, P.A., Lagna, G., Suzuki, A., and Hemmati-Brivanlou, A. 1997. Concentration-dependent patterning of the Xenopus ectoderm by BMP4 and its signal transducer Smad1. Development 124: 3177-3184.

Winnier, G., Blessing, M., Labosky, P.A., and Hogan, B.L. 1995. Bone morphogenetic protein- 4 is required for mesoderm formation and patterning in the mouse. Genes \& Dev. 9: 2105-2116.

Yamamoto, A., Amacher, S.L., Kim, S.H., Geissert, D., Kimmel, C.B., and De Robertis, E.M. 1998. Zebrafish paraxial protocadherin is a downstream target of spadetail involved in morphogenesis of gastrula mesoderm. Development 125: 3389-3397. 


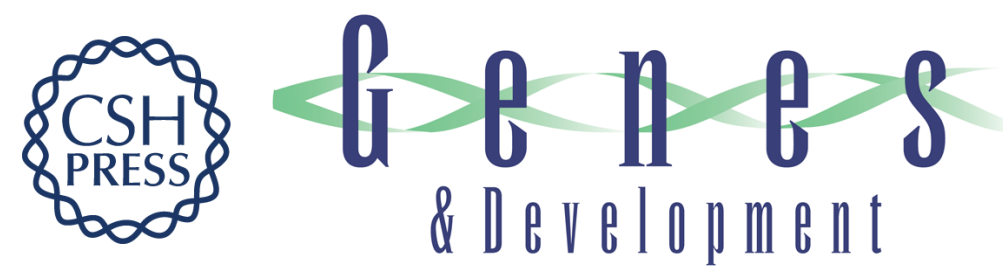

\section{Head and trunk in zebrafish arise via coinhibition of BMP signaling by bozozok and chordino}

Encina M. Gonzalez, Kimberly Fekany-Lee, Amanda Carmany-Rampey, et al.

Genes Dev. 2000, 14:

Access the most recent version at doi:10.1101/gad.852400

References

This article cites 47 articles, 21 of which can be accessed free at: http://genesdev.cshlp.org/content/14/24/3087.full.html\#ref-list-1

License

Email Alerting

Receive free email alerts when new articles cite this article - sign up in the box at the top Service right corner of the article or click here.

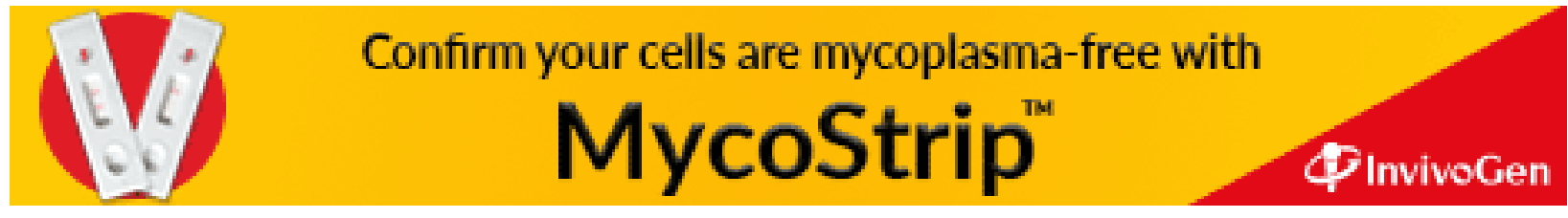

